\title{
Defining “quality of care” persuasively
}

\author{
Maya J. Goldenberg
}

Published online: 19 July 2012

(C) Springer Science+Business Media B.V. 2012

\begin{abstract}
As the quality movement in health care now enters its fourth decade, the language of quality is ubiquitous. Practitioners, organizations, and government agencies alike vociferously testify their commitments to quality and accept numerous forms of governance aimed at improving quality of care. Remarkably, the powerful phrase "quality of care" is rarely defined in the health care literature. Instead it operates as an accepted and assumed goal worth pursuing. The status of evidencebased medicine, for instance, hinges on its ability to improve quality of care, and efforts are made by both proponents and detractors to unpack the contents and outcomes of evidence-based practice while the contents of "quality of care" are presumed to be understood. Because the goals of medicine are far from obvious, this paper investigates the neglected term, "quality of care," in an effort to understand what it is that health care practices are so uncritically assumed to be striving for. Finding lack of consensus on the terminology in the quality literature, I propose that the term operates rhetorically by way of persuasive appeal (and lack of descriptive meaning). Unsatisfied that "quality of care" operates as a mere buzzword in morally contentious debates over resource allocation and duties of care, I implore health care communities to go beyond mere commitments to quality and, instead, to focus attention on the difficult task of specifying what counts as quality care within an economically constrained health care system.
\end{abstract}

Keywords Quality of care - Persuasive definition · Evidence-based medicine

\section{Introduction}

Much has been written for and against the claim that evidence-based medicine (EBM) will improve quality of care. Supporters understand EBM to necessarily

M. J. Goldenberg (更)

Department of Philosophy, University of Guelph, Guelph, ON N1G 2W1, Canada

e-mail: mgolden@uoguelph.ca 
improve medical outcomes [1] and patient choice [2], thereby improving quality of care [3]. Critics point to EBM's methodological shortcomings, and suggest that these deficiencies compromise quality of care $[4,5]$. What both sides of the debate have in common is that they focus their arguments on what is EBM, while "Quality of Care" (QoC) is taken to be understood-we presumably know it when we see it. The status of EBM as either an objective tool for improving health care or a politically and economically driven mechanism is thought to determine whether QoC is improved or diminished. This paper adds to the debate over the relationship between EBM and QoC by turning the focus onto the neglected term, QoC. I investigate usage of the term QoC in the quality assurance literature and consider how its underlying values fit with the priorities of the EBM movement. Reviewing the most heavily cited definitions of the term, I find inconsistent approaches as well as ambiguous and unsupported content. I conclude that there is one overarching feature defining QoC; it is neither content nor approach, but rather, the term's rhetorical power. Specifically, I argue (following Michael Loughlin's analysis of persuasive definitions [6]) that "quality of care" operates largely as a rhetorical device that attaches legitimacy and justification to service and policy initiatives by verbal association. Indeed, the term operates much like "evidence" does in the EBM debates, suggesting that the relationship between EBM and QoC has more to do with the persuasive appeal of the goals of both health care movements rather than the contents of how either is poised to transform health care services and delivery.

\section{Evidence-based medicine and quality of care}

If we accept the popular definition of EBM as "the conscientious, explicit and judicious use of current best evidence in making decisions about the care of individual patients," which "integrates the best evidence with individual clinical expertise and patients' choice" [7, p. 71], its compatibility with QoC seems apparent. Regardless of what QoC actually means, we know it refers to properties of the health care encounter that most of us would find valuable. Similarly, evidence based medicine owes its popularity to the promise of revamping flawed systems of health care delivery in order to provide the kind of care that most of us find valuable. EBM's promise is quality care. The definition of EBM provided above lists some of those properties that patients, providers, and policy makers find valuable: best evidence, clinical expertise, and patient choice. It is therefore unexceptional to learn that "[i]t is generally taken for granted that evidence-based medicine....will improve quality of health care" [4, p. 244].

In "Evidence-Based Medicine and Quality of Care," Dickenson and Vineis [4] never define "quality of care," yet we can extract from their analysis that they take QoC to be comprised of the following characteristics: (1) quality evidence, (2) duty of care, (3) patient choice and involvement. While these criteria seem reasonable, the next section of this article will take issue with the widespread tendency to quietly assume that the concept of "quality of care" does not require any sort of analysis. But I will set that aside for the time being. In the authors' challenge to the rarely questioned compatibility of QoC and EBM, they rehearse familiar critiques of 
EBM on all three of those points, thereby undermining that seemingly obvious relationship between evidence-based practice and quality of care. The evidencebased methodological stronghold on "quality evidence," for starters, is vigorously challenged in the medical humanities literature, as theorists find the privileging of randomized controlled trials and meta-analyses of these trials problematic. Critics argue that (1) there is no universal "gold standard" for all biomedical research, as different research questions call for different methodologies [8, 9]; (2) while randomized controlled trials minimize certain kinds of biases (ascertainment and selection), they do not guard against numerous other biasing influences [10, 11]; (3) meta-analyses amalgamate but do not correct against flawed research data [12]; (4) EBM invites evidentiary deficits in areas of health care research that are not easily amenable to randomization and blinding [13, 14]; (5) most randomized controlled trials are funded by drug companies, and therefore the highest grade of evidence suffers from funding bias and bias towards pharmaceutical interventions for health care [15-18]. In short, we may agree that a necessary (but not sufficient) criterion for quality care is the best evidence, but there is no unambiguous agreement that evidence-based medicine provides that sort of quality assurance.

Regarding the second characteristic of quality care, the doctor's duty of care, some commentators find a tension between EBM and this duty [4, 5]. Dickenson and Vineis [4] and Rogers [5] highlight difficulties between the population focus of EBM and the individual focus of the physician's duty to the patient. Evidence-based practitioners are directed to make recommendations that are derived from average estimates of effects, that is, ascertained from population-based trials. Whether "straightjacketed" [19] or merely guided by "quality" clinical guidelines, the physician is expected to defer to the likelihood that the patient will respond similarly to the majority of subjects in the relevant trials, knowing full well that the inference may be wrong. This clinical "reality" does not compromise the physician's duty to the patient. But there can be a genuine tension between the physician's clinical judgment and personal knowledge of the patient and the guideline recommendations. Some critics lament the quieting of "tacit knowledge" and "know-how" from clinical considerations [20]. However, proponents of EBM prefer evidence-based judgment over intuitions or unsupported hunches that one's patient may respond more favorably to a different course of treatment [21-24]. If anything, EBM calls for rational justification of one's decisions, and that is probably a good thing $[4,25]$. Strict adherence to guidelines and recommendations, however, can constrain rational thought, thereby not serving the patient well [26].

Finally, quality of care involves patient choice and involvement. The evaluation of EBM's connection to quality of care must consider how EBM contributes to or inhibits autonomy. Following on the previous point that EBM requires physicians to justify their recommendations based on the evidence, paternalism may be circumvented. Evidence-based practice, therefore, "has the potential to enhance the power of patients and aid the development of an increasingly effective patientcentered health care" ([27] in [4, pp. 247-248]). But this optimistic position assumes that more information will necessarily lead to rational patient choice in favor of the best therapeutic outcome. In this scenario, the duty of care and patient autonomy are never in tension and EBM enhances both of them [4, p. 248]. Yet 
there is always the potential for discord between the two. Patient consent laws recognize that patient preferences ultimately determine action (at least insofar as the patient can refuse treatment). There is the worry that the paternalistic physician can push her treatment agenda onto a patient differentially, using an evidence-based artillery of statistics, evidence, and other apparatuses of science [4, p. 248]. Relatedly, patient choice may be reduced just because the evidence only considers certain treatment options (i.e., those that are amenable to randomized controlled testing and "hard" outcome measures) or the evidence for certain options just does not exist [28]. The decisions regarding what treatment options get tested, recommended, and how they are presented are value-laden decisions that may not concur with the values of the patient [29]. Furthermore, because patient choice does not justify the patient's access to any treatment option, just the right to refuse the option presented to her, the streamlining of therapeutics by way of clinical guidelines can further reduce most patient choices to a "take it or leave it."

The potential of EBM to enhance patient autonomy requires patient involvement much sooner in the decision-making process. Rather than presenting the patient with a final choice to accept or reject a pre-packaged evidence-based recommendation, patient- and community-based representation should begin much earlier in the decision-making process, particularly in setting priorities for research, selecting the outcome measures and foci for systematic reviews, as well as determining which non-clinical values get incorporated into the conclusions drawn from meta-analyses [27, pp. 55-56; 4, p. 250].

In conclusion, the link between EBM and quality care remains undecided as long as methodological tensions persist regarding the criteria for "best evidence" and difficulty remains between EBM, the duty of care, and patient choice. Following evidence-based methods might encourage the well-meaning physician to promote drug-based treatment regimes just because the best evidence is slanted towards pharmaceuticals rather than community-based, talk-centered, or nursing-intensive options. It has been recognized that "some treatments may become the norm not because they are actually better, but because the evidence for them is better" [4, p. 259]. The patient may fare well, but overall quality of care may still be compromised if this intervention is not her preferred mode of care.

\section{Why do we need a definition of quality of care?}

"No-one is opposed to quality. How could anyone be...?" [30, p. 91]. Statements like this one give philosophers and other critical thinkers pause even though the statement appears to be correct. We understand quality to be something that we value, and therefore, opposing it seems absurd. Yet complacency should be rejected given the ubiquity of the term in contemporary health care (as well as industrial sectors) and the implications of the term's usage. Health services management places a lot of weight on the term "quality" as both a goal in itself and a pronoun describing various health care desiderata like "improvement," "assurance," "care," and "evidence." A veritable industry of health care "quality" exists—with sophisticated-seeming "quality measures" and "quality indicators," a lingo of 
"continuous quality improvement," and quality governance efforts like accreditation and institutional report cards, all of which are supported by a "science of quality measurement" [31-33], a philosophical framework called "total quality management" $[34,35]$, and a driving "quality movement" [36]. This makes the previous observation about the obvious goodness of "quality" suspicious and the suggestion that it warrants no analysis or examination should be rejected. This is precisely because quality holds widespread rhetorical appeal.

For this reason, I will bracket the previous argument that EBM does not serve to enhance QoC not because Dickenson and Vineis's analysis is problematic but because the authors do not adequately define the latter term. Without doing so, they merely demonstrate that EBM does not meet its own criteria for optimal patient care. I will return to the authors' challenge of the presumed association between evidence-based practice and quality of care once the latter term has received adequate analysis.

I begin the analysis of QoC by investigating past efforts to define the term. Surprisingly, the health quality literature does not offer a precise and conclusive definition. The quantity of literature tasking to define "quality of care" is surprisingly thin in comparison to the available literature applying the term to various measurement schemas, indicators, and models of evaluation. Only a small subset of papers puzzle over its definition [37-40]. One of the authors describes the task of defining QoC as "mission impossible" [38].

There is widespread acknowledgement that defining the term is extremely difficult to do. Joss and Kogan, for example, begin their text Advancing quality: Total quality management in the National Health Service with the admission that "the quest for quality is made more testing by the difficulty of defining it" [35, p. 5]. Donabedian admits that "quality of care is a remarkably difficult notion to define" [41, p. 692]. No one seems satisfied with the efforts that have been made, yet a few attempts get regularly cited. The next section offers a review of the most cited definitions followed by an analysis of trends and themes that have arisen in the efforts to define this allegedly notoriously difficult yet heavily utilized term.

\section{Past definitions of quality of care: review and analysis}

The definitions of Quality of Care listed below were selected because they are the most heavily cited in the quality literature:

1. American Medical Association (AMA), Council of Medical Services, 1986: "...care which consistently contributes to the improvement or maintenance of quality and/or duration of life" [42, p. 1032].

2. Institute of Medicine (IOM), 1990: "Quality of care is the degree to which health services for individuals and populations increase the likelihood of desired health outcomes and are consistent with current professional knowledge" [43, p. 21].

\footnotetext{
${ }^{1}$ Total quality management (TQM) is a management philosophy geared at continuous improvement of the quality of products and processes.
} 
3. Avedis Donabedian, in "The Quality of Medical Care: A Concept in Search of a Definition," 1979: Maximization of the benefits over risks of both technical and interpersonal aspects of patient care [44, p. 277].

4. G. E. Steffen, in "Quality Medical Care: A Definition," 1988: "Quality medical care is the capacity of the elements of that care to achieve legitimate medical and non-medical goals ... set by the patients in consultation with the physician" [37, p. 56].

5. Agency for Healthcare Research and Quality (AHRQ), 2005: "What exactly is health care quality? We know that quality means different things to different people. Some people think that getting quality health care means seeing the doctor right away, being treated courteously by the doctor's staff, or having the doctor spend a lot of time with them. While these things are important to all of us, clinical quality of care is even more important. Think of it like this: getting quality health care is like taking your car to a mechanic. The people in the shop can be friendly and listen to your complaints, but the most important thing is whether they fix the problem with your car" $[45$, p. 1].

The AMA's definition [42] is uninstructive because it defines the complex term in question, "quality of care", with an equally imprecise evaluative term, "quality of life." The relatively heavy citation of this definition without mention of this problem (see, for example, [46-48]) suggests that there is a shortage of critical thinking regarding the meaning of this important concept within the health quality literature, despite this being the very concept on which the disciplinary effort rests.

The IOM's definition is probably the most widely cited and accepted among the available definitions of QoC, and it is thought by some to be a robust and useful reference in the formulation of practical approaches to quality assessment and improvement [39, 49]. Yet this definition makes QoC's normative content seem obvious-desirable, shared by all, and unchallenged within the ranks of academic and clinical medicine. This interpretation is problematic, as conflicts surrounding clinical and policy-level discussions of QoC are plentiful. Members of health care teams often disagree among themselves regarding what constitutes high quality care for the same patient, as even the "technical" side of patient care is contested with respect to the status of scientific knowledge of the standard of care. The "interpersonal" considerations invite even more dispute by the patient and/or family members [44].

The IOM does not offer support for its position that "quality" is dependent on a standard of care [43], even though this view is challenged by patient-centered definitions such as that offered by Steffen [37]. The AHRQ concurs with the priority placed on clinical standards. Printed in a consumer's guide to health care quality, the definition suggests that while patient-centeredness matters to overall assessments of quality, the patient ought to be more concerned about the standards of best practice being met in each and every health care encounter. The mechanic analogy is followed by treatment-specific guidelines. It states, for instance, that the following five measures can be used to assess quality of care for diabetes. "If you have diabetes, you should receive the following tests and exams: regular hemoglobin A1c (blood glucose) testing, regular cholesterol testing, annual retinal 
eye exam, annual foot exam, annual flu shot" [45]. As if unable to anticipate conflicting views regarding the definition of the term, the IOM further offers no justification for why measures of quality should place weight on outcomes alone rather than on process as well (as seen again in Steffen [37]). Without the necessary justification in place, it is unclear why the IOM's definition is so widely accepted.

Avendis Donabedian, a figurehead and pioneer in the field of health care quality management, influentially parsed patient care into two components: technical and interpersonal $[41,44,50]$. The quality of technical management, he explained, depends on the balance of its expected benefits and risks, while the quality of the interpersonal process consists in conformity to legitimate patient expectations and to social and professional norms. ${ }^{2}$ He surprisingly assumed that patient expectations and social and professional norms easily conform to and result in "social and personal benefit." Thus, "a unified definition of quality can be derived by including the benefits and risks of both aspects of care" [44, p. 277]. Like the IOM definition [43], Donabedian failed to see potential sources of conflict between competing perspectives on what counts as "quality." Furthermore, this operational definition only holds insofar as more terms need to be defined-namely, what are the "expected benefits" and "expected risks," what patient expectations are "legitimate," and which social and professional norms trump if competing goals arise.

In "Quality Medical Care: A Definition" [37], Steffen charted new ground by arguing that quality was not a feature of certain properties of an object, but rather the term is defined as the capacity of those properties to achieve goals. Accordingly quality care was defined as the capacity of that care to achieve legitimate goals [37, p. 56]. Like Donabedian, he offers an operational definition dependent on which goals are chosen and who chooses them, but unlike the former, he offers a frame of reference. Steffen opts for a patient-focused perspective, where goals are "set by the patients in consultation with the physician" [37, p. 56].

These definitions differ not only in the contents and measures of quality care but also with respect to the very nature of quality-specifically, is "quality" a property or a preference? According to Donabedian, quality is a property that medical care can have in varying degrees. The degree of quality is determined by the extent to which the benefits outweigh the risks. Steffen, alternatively, understands quality to imply preference. He writes that "we prefer one object over another because the properties of the preferred object give it the capacity to satisfy a need or prefer a function or, in short, the capacity to achieve a goal" [37, p. 56]. Thus quality is not the property or the object or the goal [37, p. 56]. Rather, quality is the capacity of the object to achieve a goal.

Yet the property/preference divide often gets muddled in the discussions over definition of QoC. After defining the term, Donabedian then slips between a metaphysical concept (i.e., property/characteristic) and an evaluative concept of "quality." After dividing care into its technical and interpersonal components, he asserts that quality is "a property of, and a judgment upon, some definable unit of

\footnotetext{
${ }^{2}$ In another venue, Donabedian elaborates on the quality of the interpersonal component of care to involve "excellent" communication, trust, and the treatment of the patient with "concern, empathy, honesty, tact, and sensitivity" [50].
} 
care" [44, p. 278]. Seemingly unaware of this slippage, where he offers two disparate definitions, he then drops the former and focuses on the second: "It is necessary, next, to say what constitutes quality or goodness in each of these parts [of care]" [44, p. 278]. In short, he offers different understandings of quality-as a "property" and as a "preference"-in the very same manuscript.

A look at the dictionary definition of "quality" helps explain this conflict and confusion over the term's meaning as property or preference. Merriam-Webster defines the term as both "an inherent feature: property" and "a degree of excellence: grade" [51], suggesting that either use of the term is appropriate. Health care quality discussions, which inform allocation and policy decisions, would benefit, however, by ceasing to equivocate between the two. Does our interest in quality of care refer to the properties (or primary qualities) that the object (health care) possesses independent of our perception, or are we judging health care to have "quality" insofar as it achieves pre-defined goals?

Steffen holds that one's goals determine which properties of the object matter. Furthermore, because we may agree on the properties of a health care encounter (i.e., the standard of care was or was not met, the physician did or did not listen to the patient's concerns), but not on the calibre of that encounter, we do not mean quality in the sense of properties. Instead, we are concerned with quality in the preferential sense [37, p. 58].

In another paper by Donabedian [50], this time on the more comfortable topic of quality assessment, he offers only a quick foray into the knotty problem of defining QoC yet offers an influential piece of insight. He asserts that "several formulations are both possible and legitimate, depending on where we are located in the system of care and on what the nature and extent of our responsibilities are" [50, p. 1744]. Blumenthal [39] elaborates on this context-dependent view: physicians, for instance, regard quality to be a measure of the excellence of the services they provide and the quality of their interactions with patients. Organizations and health plans "emphasize the optimal functioning of systems when they define quality of care" [52, p. 1148; for more detail, see [39]). Similarly, Anderson explains that "employers define quality in terms of value obtained for their health care dollars. For the patients, quality means ... feeling better. To hospitals, quality is achieved when a patient goes home ... before he exceeds his D.R.G. [Diagnosis Related Group] limit" [37, p. 56]. This context-specific understanding of quality is consistent with Steffen's position that quality can only be understood with reference to a goal, adding that those goals are set according to the stakeholder's position within the health care system.

Context can be construed more broadly than stakeholder-dependent when criteria for "quality of care" are also dictated by "social norms" or conventions. Donabedian first suggested that "the definition of quality ... is, ordinarily, a reflection of values and goals current in the medical care system and in the larger society in which it is a part" [41, p. 692]. Indeed, clinical standards of care and patient input, each held to primacy by AHRQ [45] and Steffen [37], respectively, are established benchmarks in this age of evidence-based health care and patientcentered care. 
A final consideration for this analysis of past efforts to define QoC is what I will call the "catalog approach." Despite a weak attempt by the AMA to define "quality of care," within the same publication, the AMA still managed to offer insight by identifying the specific attributes of care that should be examined in determining its quality: health promotion and disease prevention, timeliness, informed participation of patients, attention to the scientific basis of medicine, and the efficient use of resources. This catalog approach, which recurs in other quality assurance writings, does not offer a definition per se (and the AMA, at least, is all the better for it), but it helpfully provides at least some guidance for policy and allocation purposes. The specific contents of these lists, notably, are rarely accompanied by detailed justification for the chosen criteria and not others. They are presumably thought to be consistent with social norms and values and therefore to not warrant further discussion.

Some commentators see the catalog approach as helpfully offering a way to avoid the difficulty of defining "QoC." The Health Services Research Group (HSRG), epidemiologists at a major health science center in Toronto, Canada, concluded that "any definition must be incomplete and arbitrary" [53, p. 2154]. They suggest instead that "quality pursuits' be focused on assessing needs and identifying problems, defining the goals of care, recognizing the attributes of care deemed to be important, designing measures to assess these goals and attributes, and responding to the results" [53, p. 2154].

Others have recommended a similar approach to quality analysis. Caper, for instance, proposed that, in the interest of serious dialogue, the word "quality" be banned from discussion about medical care and replaced by "identification and measurement of the components of quality," which include efficacy, appropriateness, and caring [54, p. 54]. Donabedian made a distinction between structure, process, and outcome in the measurement of quality of care [50]. After reviewing and dismissing previous efforts like those just mentioned for offering no more than shallowly justified lists of the components of quality of care, the HSRG then offers its own minimally justified list of the components of care. The six elements in the assessment of the quality of health care are: (1) accessibility, (2) coordination and continuity, (3) comprehensiveness, (4) patient-centeredness, (5) effectiveness, (6) efficiency [53, p. 2154].

Because the components are consistent with the norms and values currently guiding (ideal) health care practice, they seem to meet the standard of "quality," yet they do not stand as more justified or superior to other catalogs of the components of quality of care. And by abandoning the task of defining QoC, we still do not know what quality of care means and therefore have little grounds for appealing to one catalog of components over another. Furthermore, a definition qua list of traits offers no guidance as to the ranking of traits should they ever conflict. For example, if QoC includes, following the HSRG's recommendations, patient-centeredness and effectiveness, how do we mediate the conflict that arises when an intervention provides optimal patient satisfaction but does not adhere to clinical guidelines?

What, finally, are we left with in this analysis of commonly cited definitions of QoC? We have a list of traits and characteristics, none of which are found in all five of the selected definitions. While some themes converge, no one characteristic 
qualifies as either a necessary or a sufficient condition of QoC. At most, we can draw the unremarkable conclusion that quality is something we strive for in the care context. This finding is trivial, as it merely speaks to how we understand the term "quality" and recognizes the adoption of quality language in the health care context. It fails to inform any feature of health care, however, which is the topic at hand. This finding will soon be shown to support my thesis that the quality of care terminology is largely rhetorical; specifically, it operates persuasively.

\section{The quality movement}

The lack of consensus on the definition of "quality of care" is puzzling in lieu of how the term has been operationalized in health care. Health quality management is a flourishing discipline amidst a celebrated quality movement in health care. This movement was described in a 1999 editorial in the New England Journal of Medicine:

A vibrant movement to improve quality has sprung up in the United States. Report cards on health plans, hospitals, medical groups, and even individual physicians have appeared on the front pages of newspapers, on television, and on the Internet. Projects to solve problems of quality within health care institutions dot the health care landscape. A small but determined cadre of physician leaders has developed a science of health care quality and is working to transform that science into a national movement. [36, p. 488]

This phenomenon was occurring concurrently in Canada and the UK as well. Because quality problems were being highlighted at the organizational level, organizational quality as a managed process was the solution. This framework for understanding and remedying "quality" apparently required no justification.

Bodenheimer [36] describes two general strategies employed for quality improvement: one involving external pressures on organizations for improved quality from government regulators and private purchasers in such efforts as accreditation, audit, and (preferably publicly available) report cards. The second strategy is to improve quality from within — creating a "culture of quality" within an organization. Institutional executives and administrators are encouraged to introduce systems to reduce the number of errors and to minimize adverse consequences of those errors that unavoidably occur. Reminder systems on patient records are one such example of an error-minimizing effort [36, p. 492]. Goals are set for error occurrences-for example, Chassin's "six sigma" challenge of fewer than 3.4 errors per 1 mission event (a rate that lies outside of six standard deviations of a normal distribution) [55, p. 571]. Meeting this goal requires more than just conscientious and careful individual health care staff. Instead, investment needs to be made for technologies like electronic patient records with automated reminders and staff need to be cajoled into taking responsibility for encouraging that culture of quality [36, p. 491].

The quality movement drew lessons from industry and philosophies of management to refine its effort to elevate its standards of performance. Medicine 
had historically taken a "watchdog approach," enlisting such techniques as licensing, professional accreditation, internal audits, and external inspections to identify and solve problems [56]. Berwick refers to this as quality by inspection, a framework that achieves quality by removing "bad apples" [57, p. 53]. Industry had taken a more active approach since the mid-twentieth century: training employees to prevent problems, strengthening organizational systems, and continually improving performance [57, p. 53]. This method emphasizes continuous improvement, and "calls for understanding and revision of the production process rather than placing blame on the individual" [57, p. 53]. In the 1980s, health care began importing these quality enhancing techniques into its fold [56].

Reflecting on what spurred this movement, Brook points to academic debates regarding the persistence of poor quality and variations in health services that intensified in the 1970s [58, p. 1831]. This climate suggested that novel action was required. But the global recession of the 1980s likely did more to motivate change. Most policy leaders subscribed to a "waste theory"- the conviction that much of rising health care costs could be explained by inefficient and inappropriate use of services [59]. It is still widely maintained that clinical effectiveness and cost-control can go hand in hand.

Sociologists have previously characterized medical coalitions and segments as social movements [60-62]. Catherine Pope, most recently, has demonstrated that evidence-based medicine meets the criteria for a social movement, which she, following Blumer [63], defines as "collective enterprises to establish a new order of life" ([63] in [62, p. 268]). Blumer influenced sociological studies of social movements with his five mechanisms for a social movement's formation and growth:

1. Agitation: "a means of exciting people and awakening within them new impulses and ideas that make them restless and dissatisfied" ([63] in [62, p. 269])

2. Common or shared experience

3. Enduring sense of purpose (to sustain the movement)

4. Clearly articulated goal

5. Strategies for the movement to achieve its goals

The "agitation" that impelled the quality movement is captured in the enduring feeling that the system needs fixing. Wachter encapsulates this common sentiment in his description of the motivators of the quality movement: "Driven by evidence that US medical practice comports with best evidence approximately half the time, that large numbers of medical errors continue to occur, and that clinically indefensible disparities in care exist across regions and racial and ethnic groups, health care payers and the US government have decided that quality should be measured, publicly reported, and perhaps even compensated differentially [i.e., payfor-performance]" [64, p. 2780]. The second mechanism-the common or shared experience-is captured in the stories of frustrated clinicians who feel that they cannot serve their patients adequately and in patient narratives describing failures in the system. The enduring sense of purpose, the third mechanism for social group formation, is presumably the importance of minimizing "overuse, underuse, and 
misuse" [65, p. 3472] of health care resources, thereby improving care and controlling costs, harm, and waste. Fourth, the clearly articulated goal is "improve quality!" a laudable goal accepted by all even if we do not know exactly what quality means. Finally, the goal-oriented strategies carrying the movement are the collective of quality management measures, techniques, and efforts. As Wachter describes it, the "scientific underpinnings of quality measurement are rising to the task [of quality improvement]" [64, p. 2780]: "Donabedian's insight to divide quality into structure (how care is organized), process (what was done), and outcomes (what happened to the patient) is the quality movement's scaffolding. Its planks are thousands of research studies linking certain structures or processes to clinically meaningful outcomes" [64, p. 2780]. While perhaps lacking the characteristic charismatic leader of a social movement, the quality movement compensates with a persuasive message: quality matters!

Even without a concrete understanding of what quality means, everyone seems to agree that it is something worth organizing ourselves around, and that it ought to be monitored, measured, and improved. The quality movement is founded on the belief (and frustration) that quality in health care is poor and that it can (and should) be improved.

As for why evaluative science provides the means for doing so, the logic is not clear. The National Committee for Quality Assurance, an American provider of publicly accessible report cards on NCQA- accredited health plans, surmises: "Why is it so important to measure health plan performance and quality? The answer is simple: Quality improves when you measure" [66]. They do not elaborate on why this is the case. They presumably are not referring to the phenomenon of "playing to the test," where clinicians and organizations undertaking such measurement exercises change their own behavior, thereby improving on the very quality measure that they have highlighted as needing improvement. Nonetheless, the quality movement's problem, method, and desired outcome have been determined even if it is in want of a definition of "quality of care." A "movement," of course, gets everyone "on board." But with "quality" being so imprecisely defined, one must ask: what exactly are we moving towards?

\section{Quality of care: a persuasive definition}

What really brings this movement together? I want to suggest that it is no more than the persuasiveness of "quality." The rhetorical power of the term explains why no definition is needed to invoke the mechanisms of social movement formation.

The difficulty surrounding the task of defining QoC is now apparent-a number of proposals have been made but with little justification for one definition over another, no one account seems to endure. The "cataloging" maneuver of not defining the term but instead indicating what quality refers to does not successfully avoid the problem of defining it. If we do not know what QoC means, we cannot evaluate which attributes or characteristics are properly referred. There is little ground for resolution when competing catalogs arise. 
What makes a good definition? Loughlin proposes that a good definition explains the meaning of a term to someone who did not already know it. It would serve as a guide to future usage, ruling out some uses in advance by distinguishing appropriate from inappropriate uses [6, p. 72, 67, p. 92]. The definitions of QoC examined in this paper fail on both counts. Those that lack the specificity to delineate "good quality" from "bad quality" (i.e., because they define the term using other operational terms like "excellence," "risk," and "benefit") do not inform the uninformed as to what the term means. The other definitions lack justification for their own account of quality over competing contenders and, therefore, cannot justify future usage or delineations of appropriate from inappropriate uses. What these definitions have in common, and what gets them cited in the quality literature without critical comment, is the same thing that makes the accompanying science flourish and the movement persist: the emotive content and persuasiveness of the promise of quality.

Loughlin [6] first noted the persuasive nature of the language of quality in health care, borrowing from 20th century American philosopher C. L. Stevenson. As an emotivist, Stevenson understood moral judgments to denote exclamative sentences (e.g., "hurray!") that expressed the speaker's affective states, for instance, an expression of approval. Moral claims like "stealing is wrong," therefore, mean something like "stealing: boo!" With this attention to non-rational language and meaning in place, Stevenson investigated the use of "moral persuasion" as a linguistic method for settling disagreements and creating consensus [68]. By invoking the emotive elements of words, persuasion can redirect attitudes and change behavior without appeal to factual content or descriptive meaning. At the center of this non-rational reform technique is the "persuasive definition" [69].

Many terms have two elements to their meanings: descriptive/factual and emotive/ evaluative. The emotive element affects our attitudes, causing us to approve or disapprove of whatever it is applied to, thereby affecting our behavior [6, p. 72]. Persuasive definitions capitalize on this emotional content. For example, the word "democracy" has an emotive aspect to its meaning; if a government can convince the people that it is democratic then we are more likely to accept its governance [70]. Persuasive definitions can take over when the descriptive meaning of a term becomes vague or unclear but it continues to carry emotive force. To define a term persuasively is "to offer as an 'explanation' of the meaning of an emotive term what is in fact a proposal for a revision of that term's descriptive meaning" [6, p. 72].

"Democracy," once again, illustrates this phenomenon. Its descriptive meaning has become vague enough for ideologically diverse leaders and political systems to claim to be the "truly" democratic choice for their respective constituents. We see that the descriptive meanings of "quality" and "quality of care" are vaguer still, while the emotive force is as strong as ever. Who can disagree with the claim that quality matters or that health care institutions ought to be committed to quality? When that persuasive term is attached to specific content (a type of health care intervention or interaction, for instance), the "factual" content is likely to be accepted by those who have already been persuaded. No more than verbal association has made that health care intervention an instance of quality care.

What Stevenson highlighted was how rhetoric can change attitudes. Loughlin's interest in persuasion has more to do with how emotional appeals can shelter 
opinion leaders in the health sector from critique. While general claims about quality (like "quality matters!") are easy to accept, specific claims about what counts as "quality care" can be contested. Indeed, this is frequently the case when quality language is used to justify rationing exercises. Careful persuasive use of the language of "quality" can quiet dissent. Attaching evaluations of "quality" to certain practices "can create an atmosphere in which it seems unreasonable to question or criticize" [6, p. 72]. And this is what Loughlin seems to think is the real lesson taken by the health care sector from industry and managerial studies-a lesson in marketing. The business "gurus" achieved a way of labeling products as "quality" so that people would buy them. Health care managers and government stand to gain from this kind of public acceptance in times of cuts to services and critical budgetary deficits.

At this point, I am ready to propose a new persuasive definition of QoC: Quality of care refers to the attributes of a health care service that are taken by the relevant stakeholders to be important enough to be measured and promoted within an organization. This definition is somewhat similar to some of the previously analyzed definitions insofar as it fails to specify the meaning of the term. But unlike the previous "catalog" pseudo-definitions, this effort additionally fails to even attempt to list meaningful referents. This presumably makes this definition more easily acceptable, as there is no content that could be objectionable to any of the competing stakeholders' interests. This definition serves to justify quality initiatives at any level of health care organization, offering no more than the widely accepted sentiment that quality is important! Because no one opposes quality as a general objective (because quality is important), this is all the justification that one needs.

It is when we get into specific claims regarding which treatments, procedures, and priorities characterize "quality" care that disagreement will almost surely occur. This definition avoids any such discontent by limiting itself to the praiseworthiness of "quality" as a feature of any organization. Once an organization has positively associated itself with a commitment to quality, specific content can be introduced under the auspices of "quality."

My offer of a persuasive definition of quality of care was undertaken in jest. I offered the kind of definition that should not be entertained in the health quality assurance literature. The new definition improved on the rhetorical power of previous definitions by offering no logical room for dissent. I avoided all potential points of disagreement by taking no position on whether the term refers to process or outcome, property or evaluation. I also offered no potentially controversial position on the content or context of quality care. In other words, the descriptive meaning of the term was vacuous. Stripped down to nothing but persuasive language, descriptive meaning can be carefully attached to the term by savvy policy makers.

\section{Evidence-based practice and quality of care}

"No one is against EBM (who can in the 21th century be against evidence?)" [71, p. 134]. "No-one is opposed to quality. How could anyone be...?" [30, p. 191]. 
These comments speak to a parallel in the rhetorical appeal of two seemingly innocuous terms- "evidence" and "quality"-insofar as they both seem too familiar to warrant analysis and too obvious to legitimate dispute. Each term similarly supports a major health care movement_- "evidence-based medicine" and the "quality movement"-thereby suggesting that the implications of both seemingly obvious terms are significant.

Among the many responses to EBM, an often heard retort is, "evidence-based medicine? What other kind of medicine can there be?" This kind of commentary has been launched as a criticism of the movement-the charge being that EBM offers nothing new (see, for example, [72]). However, I see the seeming obviousness of evidence-based decision-making, that is, the task of basing medical decisionmaking on the most current and rigorous evidence, to be amongst the movement's greatest strengths. It goes a long way to explaining much of evidence-based practice's resounding success with regards to rapid acceptance and uptake by the health sciences and clinical practice. EBM introduced numerous methodological innovations to health care, including the hierarchy of evidence, the "gold standard" status of the randomized controlled trial, and the reorientation of medical research from a bench science focus on pathophysiological rationale to outcomes research and outcomes measures [73]. However, it was not these methodological details but, rather, the appealing promise of making medicine more responsive to the evidence, and thereby improving the quality of patient care, that caught the attention of the health care community and generated such strong approval. Cloaked in a name that makes it difficult to argue against, EBM could be embraced or dismissed as an uncontroversial appeal to making clinical practice more responsive to the research findings. Either response leaves the philosophical underpinnings of the movement, and some very radical pedagogical and methodological techniques, largely unexamined within the mainstream health literature. Strong epistemic challenges have been confined to the pages of medical humanities and social science journals (with the exception of the Journal of Evaluation in Clinical Practice). With a name as obvious as "evidence-based medicine," and a promise as appealing as ridding medicine of its faulty and untested habits and practices, it is easy to overlook the factual content that EBM brings to clinical practice. Yet when a redrawing of the nature and future of medicine is being proposed, critical examination is warranted! It is the persuasive element that quiets responsible investigation.

Just as no one with even minimal trust in scientific procedure is against evidence, no one is against quality either. "Evidence" and empirical inquiry separate science from other knowledge pursuits. "Quality," more pronouncedly, requires no prior commitments to science, empiricism, and the like. Quality is a good thing and is therefore difficult to oppose without seeming absurdity.

Logical as it seems, this conclusion ought to be resisted. The specific contents of quality initiatives are far from obvious. Instead these determinations require ethically challenging considerations of beneficent clinical care, informed patient

\footnotetext{
${ }^{3}$ Having said that, "evidence-based" practice involves much more than empirical adequacy (see [73]). The common interchange between "evidence-based" and "empirically-tested" in many policy documents (see, e.g., [74]) is inappropriate and misleading.
} 
choice, and distributive justice-what constitutes each and how they ought to be balanced against conflicting duties. This complex weighing of competing moral principles should be done transparently, and conclusions should be subject to critical examination by informed stakeholders. Persuasive language should not shape this important debate.

\section{Conclusion}

With the understanding that conscientious health care providers and administrators cannot be anything but committed to quality, we need to focus our attention on the difficult question of specifying what counts as quality care within any economically constrained health care system. The quality movement in health care has generated the attention needed to properly address complex health care allocation issues, but the term "quality" must operate as a benchmark and an invitation for critical discussion rather than encourage complacency through persuasive appeal.

I began this investigation by considering the debate over whether EBM helped or hindered QoC, noting that the latter term went undefined in these discussions and that, as a result, the debate in fact hinged on whether EBM met its own criteria of optimal care. Having analyzed QoC independently, I was able to properly evaluate the EBM/QoC relationship. Since the quality assurance literature demonstrates no uniformity with respect to the meaning of the term, the only attribute that seems to define the term is its persuasive appeal. Quality matters and quality of care refers to the things we take to be important in health care. It follows that EBM enhances QoC if the attributes that EBM enhances are the same attributes that we find important. Similarly, EBM does not enhance QoC if it fails to meet the health care objectives that we value. My appeal to critical investigation was a call for rational discourse, not persuasion, to determine which health care goals are worth pursuing.

\section{References}

1. Shortell, Stephen M., Thomas G. Rundall, and John Hsu. 2007. Improving patient care by linking evidence-based medicine and evidence-based management. Journal of the American Medical Association 298(6): 673-676.

2. Hope, Tony. 1996. Evidence-based patient choice. London: King's Fund Publishing.

3. Greenhalgh, Trisha. 2010. How to read a paper: The basics of evidence-based medicine. Oxford: Wiley-Blackwell.

4. Dickenson, Donna, and Paolo Vineis. 2002. Evidence-based medicine and quality of care. Health Care Analysis 10(3): 243-259.

5. Rogers, Wendy. 2002. Is there a tension between doctors' duty of care and evidence-based medicine? Health Care Analysis 10(3): 277-287.

6. Loughlin, Michael. 1993. The illusion of quality. Health Care Analysis 1(1): 69-73.

7. Sackett, David L., M.C. William, J.A. Rosenberg, R. Muir Gray, Brian Haynes, and W. Scott Richardson. 1996. Evidence-based medicine: What it is and what it isn't. British Medical Journal 312(7023): 71-72.

8. Cartwright, Nancy. 2007. Are RCTs the gold standard? Biosocieties 2(2): 11-20. 
9. Worrall, John. 2002. What evidence is evidence-based medicine? Philosophy of Science 69(3): S316S330.

10. Jadad, Alejandro R., and Murray W. Enkin. 2007. Randomized controlled trials: Questions, answers, and musings, 2nd ed. London: BMJ Books.

11. Borgerson, Kirstin. 2009. Valuing evidence: Bias and the evidence hierarchy of evidence-based medicine. Perspectives in Biology and Medicine 52(2): 218-233.

12. Stegenga, Jacob. 2011. Is meta-analysis the platinum standard of evidence? Studies in the History and Philosophy of Biological and Biomedical Science 429(4): 497-507.

13. Grossman, Jason, and Fiona J. Mackenzie. 2005. Randomized controlled trials: Gold standard, or merely standard? Perspectives in Biology and Medicine 48(4): 516-534.

14. Giacomini, Mita. 2009. Theory-based medicine and the role of evidence: Why the emperor needs new clothes, again. Perspectives in Biology and Medicine 52(2): 234-251.

15. Angell, Marcia. 2004. The truth about the drug companies: How they deceive us and what to do about it. New York: Random House.

16. Bodenheimer, Thomas. 2000. Uneasy alliance: Clinical investigators and the pharmaceutical industry. New England Journal of Medicine 342(20): 1539-1544.

17. Lexchin, Joel, Lisa A. Bero, Benjamin Djulbegovic, and Otavio Clark. 2003. Pharmaceutical industry sponsorship and research outcome quality: Systematic review. British Medical Journal 326: 1167-1177.

18. Psaty, Bruce M., Noel S. Weiss, and Curt D. Furberg. 2006. Recent trials in hypertension: Compelling science or commercial speech? Journal of the American Medical Association 295(14): 1704-1706.

19. Loewy, Erich E. 2007. Ethics and evidence-based medicine: Is there a conflict? Medscape General Medicine 9(3): 30 .

20. Henry, Stephen G. 2006. Recognizing tacit knowledge in medical epistemology. Theoretical Medicine and Bioethics 27(3): 187-213.

21. Dawson, Neal V., and Hal R. Arkes. 1987. Systematic errors in medical decision making: Judgment limitations. Journal of General Internal Medicine 2(3): 183-187.

22. Oxman, Andrew D., and Gordon H. Guyatt. 1993. The science of reviewing research. Annals of the New York Academy of Science 703: 125-133.

23. MacCoun, Robert J. 1998. Biases in the interpretation and use of research results. Annual Review of Psychology 49: 259-287.

24. Sackett, David L. 1989. Rules of evidence and clinical recommendations on the use of antithrombotic agents. Chest $95(2$ suppl.): $2 \mathrm{~S}-4 \mathrm{~S}$.

25. Upshur, Ross. 2005. Looking for rules in a world of exceptions: Reflections on evidence-based practice. Perspectives in Biology and Medicine 48(4): 477-489.

26. Goldenberg, Maya J. 2009. Iconoclast or creed? Objectivism and pragmatism in evidence-based medicine's hierarchy of evidence. Perspectives in Biology and Medicine 52(2): 168-187.

27. Ashcroft, Richard, Tony Hope, and Michael Parker. 2001. Ethical issues and evidence-based patient choice. In Evidence-based patient choice: Inevitable or impossible? ed. Adrian Edwards and Glynn Elwyn, 53-65. Oxford: Oxford University Press.

28. Bluhm, Robyn. 2010. Evidence-based medicine and patient autonomy. International Journal of Feminist Approaches to Bioethics 2(2): 134-151.

29. Molewijk, A.C., A.M. Stiggelbout, W. Otten, H.M. Dupuis, and J. Kievit. 2003. Implicit normativity in evidence-based medicine: A plea for integrated empirical ethics research. Health Care Analysis 11: 69-92.

30. Curtis, Keith. 1993. Total quality and management philosophies. In The textbook of total quality in healthcare, ed. A.F. Al-Assaf and June A. Schmele, 191-205. Del Ray, FL: St. Lucie Press.

31. Weis, Curtis J., and Luis A.N. Ameral. 2010. Moving the science of quality improvement in critical medicine forward. American Journal of Respiratory and Critical Care Medicine 182: 1461-1462.

32. Scales, Damon C., Katie Dainty, Brigette Hales, et al. 2011. A multifaceted intervention for quality improvement in a network of intensive care units: A cluster randomized trial. Journal of the American Medical Association 305(4): 363-372.

33. Berwick, Donald M. 2008. The science of improvement. Journal of the American Medical Association 299(10): 1182-1184.

34. Al-Assaf, A.F., and June A. Schmele, eds. 1993. The textbook of total quality in healthcare. Delray Beach, FL: St Lucie Press. 
35. Joss, Richard, and Maurice Kogan. 1995. Advancing quality: Total quality management in the National Health Service. Buckingham: Open University Press.

36. Bodenheimer, Thomas. 1999. The movement for improved quality in health care. New England Journal of Medicine 340(6): 488-492.

37. Steffen, Grant E. 1988. Quality medical care: A definition. Journal of the American Medical Association 260(1): 56-61.

38. Reerink, Evert. 1990. Defining quality of care: Mission impossible? International Journal of Quality Health Care 2(3-4): 197-202.

39. Blumenthal, David. 1996. Quality of care: What is it? New England Journal of Medicine 335(12): 891-894.

40. Campbell, Stephen, Martin O. Roland, and Stephen A. Buetow. 2000. Defining quality of care. Social Science and Medicine 51(11): 1611-1625.

41. Donabedian, Avedis. 1966/2005. Evaluating the quality of medical care. Milbank Quarterly 83(4): 691-729.

42. American Medical Association, Council of Medical Service. 1986. Quality of care. Journal of the American Medical Association 256(8): 1032-1034.

43. Institute of Medicine. 1990. Medicare: A strategy for quality assurance, vol. 1. Washington, DC: National Academy Press.

44. Donabedian, Avedis. 1979. The quality of medical care: A concept in search of a definition. Journal of Family Practice 9(2): 277-284.

45. Agency for Healthcare Research and Quality. 2005. Guide to healthcare quality: How to know it when you see it. Washington, DC: U.S. Department of Health and Human Services.

46. Wexler, Barbara. 2002. Health care, Quality of. In Encyclopedia of Nursing \& Allied Health, vol. 2, ed. Kristine Krapp. Gale Cengage. http://www.enotes.com/health-care-quality-reference. Accessed Mar 18, 2012.

47. Mawani, Amin. 2011. Can we get better for less: Value for money in Canadian health care. Burnaby, BC: Certified General Accountants of Canada. www.cga-canada.org/en-ca/ResearchReports/ ca_rep_2011-04_healthcare.pdf. Accessed Mar 14, 2012.

48. Daum, Wayne J., Mark R. Brinker, and David B. Nash. 2000. Quality and outcome determination in health care and orthopaedics: Evolution and current structure. Journal of the American Academy of Orthopedic Surgery 8: 133-139.

49. Institute of Medicine. 1999. Measuring the quality of health care: A statement by the National Roundtable on Health Care Quality. Washington: National Academy Press.

50. Donabedian, Avedis. 1988. The quality of care: How can it be assessed? Journal of the American Medical Association 260(12): 1743-1748.

51. Merriam-Webster. 2012. "Quality." Merriam-Webster Online. http://www.merriam-webster.com/ dictionary/quality. Accessed Feb 11, 2012.

52. Blumenthal, David. 1996. The origins of the quality-of-care debate. New England Journal of Medicine 335(15): 1146-1149.

53. Health Services Research Group. 1992. Quality of care: 1. What is quality and how can it be measured? Canadian Medical Association Journal 146(12): 2153-2158.

54. Caper, Philip. 1988. Defining quality in medical care. Health Affairs 7(1): 49-61.

55. Chassin, Mark R. 1998. Is healthcare ready for six-sigma quality? Milbank Quarterly 76(4): 565-591.

56. Kols, Adrienne J., and Jill E. Sherman. 1998. Family planning programs: Improving quality. Population Reports, Series J, No. 47. Baltimore: Johns Hopkins University School of Public Health, Population Information Program. http://www.k4health.org/pr/j47/j47chap2.shtml\#2.2. Accessed March 30, 2012.

57. Berwick, Donald M. 1989. Continuous improvement as an ideal in health care. New England Journal of Medicine 320(1): 53-56.

58. Brook, Robert H. 2010. The end of the quality improvement movement: Long live improving value. Journal of the American Medical Association 304(16): 1831-1832.

59. Mehlman, Maxwell J. 1986. Health care cost containment and medical technology: A critique of waste theory. Case Western Reserve Law Review 778: 784-794.

60. Bucher, Rue. 1962. Pathology: A study of social movements within a profession. Social Problems 10(1): 40-51.

61. Bucher, Rue, and Joan G. Stelling. 1969. Characteristics of professional organizations. Journal of Health and Social Behavior 10(1): 3-15. 
62. Pope, Catherine. 2003. Resisting evidence: The study of evidence-based medicine as a contemporary social movement. Health: An Interdisciplinary Journal for the Social Study of Health, Illness and Medicine 7(3): 267-282.

63. Blumer, Herbert. 1995 [1955]. Social movements. In Social movements: critiques, concepts and case studies, ed. Stanford M. Lyman, 60-83. London: Macmillan.

64. Wachter, Robert M. 2006. Expected and unanticipated consequences of the quality and information technology revolutions. Journal of the American Medical Association 295(23): 2780-2783.

65. Chassin, Mark R. 1991. Quality of care-time to act. Journal of the American Medical Association 266: 3472-3473.

66. National Council on Quality Assurance. 2008. Health plan report card. http://reportcard.ncqa.org/ plan/external/Resources.aspx?Header=yes\&Tab=WhyQualityMatters. Accessed March 14, 2012.

67. Loughlin, Michael. 1996. The language of quality. Journal of Evaluation in Clinical Practice 2(2): 87-95.

68. Stevenson, Charles L. 1944. Ethics and Language. New Haven: Yale University Press.

69. Stevenson, Charles L. 1963 [1938]. Persuasive definitions. In Facts and values: Studies in ethical analysis, ed. Charles L. Stevenson, 32-54. New Haven: Yale University Press.

70. Bunnin, Nicholas, and Jiyuan Yu. 2004. Persuasive definition. The Blackwell dictionary of western philosophy, 504. Malden, MA: Wiley-Blackwell.

71. Glasziou, Paul. 2006. Why is evidence-based medicine important? Evidence Based Medicine 11: 133-135.

72. Benitez-Bribiesca, Luis. 1999. Evidence-based medicine: A new paradigm? Archives of Medical Research 30(2): 77-79.

73. Goldenberg, Maya J. 2012. Innovating medical knowledge: Understanding evidence-based medicine as a socio-medical phenomenon. In Evidence-based medicine. ed. Nikolaos Sitara, 11-28. Rijeka: InTech Publications.

74. American Psychological Association Presidential Taskforce on Evidence-Based Practice. 2006. Evidence-based practice in psychology. American Psychologist (May-June): 271-284. 